\title{
Pore Structure and Influence of Recycled Aggregate Concrete on Drying Shrinkage
}

\author{
Yuanchen Guo, ${ }^{1,2}$ Jueshi Qian, ${ }^{1}$ and Xue Wang ${ }^{2}$ \\ ${ }^{1}$ College of Materials Science and Engineering, Chongqing University, No. 174 Shazheng Street, Shapingba District, \\ Chongqing 400030, China \\ ${ }^{2}$ College of Civil Engineering, Chongqing Three Gorges University, 780 ShaLong Road, Wanzhou District, Chongqing 404100, China
}

Correspondence should be addressed to Yuanchen Guo; gyc1982@yahoo.com.cn

Received 24 July 2013; Revised 4 September 2013; Accepted 5 September 2013

Academic Editor: Stefano Vidoli

Copyright (c) 2013 Yuanchen Guo et al. This is an open access article distributed under the Creative Commons Attribution License, which permits unrestricted use, distribution, and reproduction in any medium, provided the original work is properly cited.

\begin{abstract}
Pore structure plays an important role in the drying shrinkage of recycled aggregate concrete (RAC). High-precision mercury intrusion and water evaporation were utilized to study the pore structure of RAC, which has a different replacement rate of recycled concrete aggregate (RCA), and to analyze its influence on drying shrinkage. Finally, a fractal-dimension calculation model was established based on the principles of mercury intrusion and fractal-geometry theory. Calculations were performed to study the pore-structure fractal dimension of RAC. Results show the following. (1) With the increase in RCA content, the drying shrinkage values increase gradually. (2) Pores with the greatest impact on concrete shrinkage are those whose sizes ranging from $2.5 \mathrm{~nm}$ to $50 \mathrm{~nm}$ and from $50 \mathrm{~nm}$ to $100 \mathrm{~nm}$. In the above two ranges, the proportions of RAC are greater than those of RC0 (natural aggregate concrete, NAC), which is the main reason the shrinkage values of RAC are greater than those of NAC. (3) The pore structure of RAC has good fractal feature, and the addition of RCA increases the complexity of the pore surface of concrete
\end{abstract}

\section{Introduction}

Shrinkage deformation of concrete material has attracted extensive studies here and abroad with regard to the complexity of the shrinkage-deformation mechanism and heterogeneity of nature of concrete material. Although corresponding theoretical models have been built, capillary tension theory still has a more extensive application range $[1,2]$.

Recycled aggregate concrete (RAC) mainly refers to new concrete prepared by recycled concrete aggregate (RCA), which is made from construction waste, to replace or partially replace natural aggregate. Hasaba and Kawamure [3], Katz [4], Debieb and Kenai [5], Courard et al. [6], DomingoCabo et al. [7], Evangelista and Brito [8], and other experts have carried out numerous experimental studies on drying shrinkage. The same research results showed that, under the same test condition, RAC has greater shrinkage deformation than natural aggregate concrete (NAC). Coupling with the physical and mechanical property defects of RCA, RAC is rarely applied to the project instance. Thus, determining how to reduce the shrinkage and improve the crack resistance of RAC materials has become an important concern. Based on capillary tension theory, porosity and pore characteristics have great influence on the uneven shrinkage of RAC. Therefore, studying the pore structure and characteristics is particularly important in the research on RAC shrinkage.

\section{Experimental}

2.1. Materials and Mix Proportion. Cement: P.S 32.5. Construction waste $(\mathrm{CW})$ : generated from a demolished building in Chongqing City, China. Natural coarse aggregate (NCA): commercial gravel. Sand: commercial mountain sand. Table 1 shows the performance parameters of the aggregates.

C30 natural mix proportion is utilized as reference. Table 2 shows the mix design. Considering the guaranteed rate of 0.9 after standard curing of 28 days, the compressive strength of the concrete is shown in Figure 1. 
TABLE 1: Performance parameters of aggregate.

\begin{tabular}{lccccc}
\hline Type of aggregate & $\begin{array}{c}\text { Abrasion value } \\
\text { (by mass) }(\%)\end{array}$ & $\begin{array}{c}\text { Crushed index } \\
\text { (by mass) }(\%)\end{array}$ & $\begin{array}{c}\text { Moisture } \\
(\text { by mass })(\%)\end{array}$ & $\begin{array}{c}\text { Water absorption } \\
(\text { by mass })(\%)\end{array}$ & $\begin{array}{c}\text { Apparent density } \\
\left(\mathrm{kg} \cdot \mathrm{m}^{-3}\right)\end{array}$ \\
\hline RCA & 35.19 & 17.22 & 4.17 & 6.51 & 2410 \\
NA & 34.39 & 9.65 & 0.49 & 0.57 & 2630 \\
Sand & $/$ & $/$ & 0.52 & 1.59 & 2620 \\
\hline
\end{tabular}

TABle 2: Mix design of RC $\left(\mathrm{kg} \cdot \mathrm{m}^{-3}\right)$.

\begin{tabular}{lcccccccc}
\hline Project & Number & Cement & NA & RCA & Sand & Water & Sand ratio & W/C \\
\hline \multirow{3}{*}{ RCA replacement ratio } & RC0 & 426 & 1000 & 0 & 560 & 200 & 0.36 & 0.47 \\
& RC30 & 426 & 700 & 300 & 560 & 200 & 0.36 & 0.47 \\
& RC100 & 426 & 0 & 1000 & 560 & 200 & 0.36 & 0.47 \\
\hline
\end{tabular}

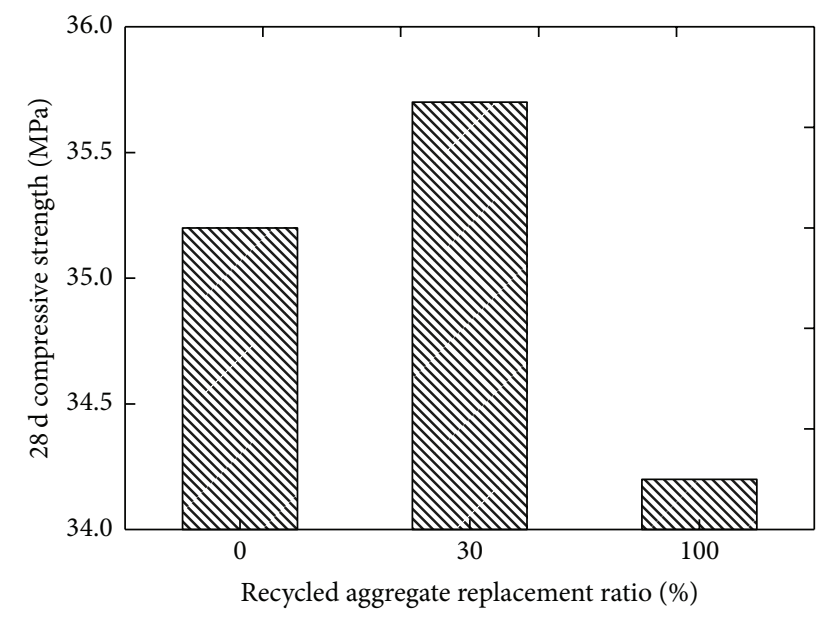

FIGURE 1: Compressive strength of concrete.

\subsection{Principle and Methods}

2.2.1. Test of Drying Shrinkage and Mechanical Properties. Drying shrinkage test of RAC is conducted according to the GB/T 50082-2009 standard for test methods of long-term performance and durability of ordinary concrete. Specimen size is $100 \mathrm{~mm} \times 100 \mathrm{~mm} \times 515 \mathrm{~mm}$. Mechanical properties of concrete are tested according to the GB/T 50081-2002 standard for test method of mechanical properties on ordinary concrete.

2.2.2. Test of Pores. Water evaporation and mercury intrusion are the two methods utilized to characterize the pore structure in this study.

Water evaporation can be utilized to determine the capillary pores and stoma whose aperture is more than $30 \mathrm{~nm}$ (referred to herein as macroporous, otherwise referred to as capillary pores) [9]. With $90 \%$ relative humidity, the water loss rate of saturated RAC specimens can be expressed as the macropore porosity of RAC [10]. In the case of $105^{\circ} \mathrm{C}$, the water loss rate of saturated RAC specimens can be expressed as the total porosity of RAC. Following this calculation, the difference between the above water loss rates can be expressed as capillary porosity.
The volume porosity $\rho$ of RAC can be calculated using

$$
\rho=\frac{V_{W}}{V_{C}}=\frac{M_{0}-M_{1}}{M_{0} \cdot \rho_{W}} \cdot \rho_{C} \times 100 \%,
$$

where $\rho$ is the volume porosity of RAC, $\% ; M_{0}$ is the saturated quality of the RAC sample, $\mathrm{g} ; M_{1}$ is the sample quality after losing the water, $\mathrm{g} ; \rho_{C}$ is the density of RAC, $\mathrm{g} \cdot \mathrm{cm}^{-3} ; \rho_{W}$ is the density of water, $\mathrm{g} \cdot \mathrm{cm}^{-3} ; V_{W}$ is the volume of water, $\mathrm{cm}^{3}$; and $V_{C}$ is the volume of concrete, $\mathrm{cm}^{3}$.

Specimens after standard curing were crushed into $3 \mathrm{~mm}$ to $5 \mathrm{~mm}$ particles, rinsed, and then dried in gradual rising temperature. Next, the pore structure was tested by AUTOPORE 9500 automatic pressure mercury analyzer. Pore size range measured utilizing the instrument was $0.003 \mu \mathrm{m}$ to $1000 \mu \mathrm{m}$.

Under atmospheric pressure, mercury can only enter open pores whose radius is greater than $7 \mu \mathrm{m}$ because of the resistance of surface tension. External force must be applied to overcome the surface tension and make the nonwetting liquid mercury enter a narrow capillary force [11], as shown in Figure 2.

\section{Results and Discussion}

3.1. Drying Shrinkage of RAC. The tests results are shown in Figure 3.

Figure 3 shows that, with the increase in RCA content, drying shrinkage values tend to increase gradually.

3.2. Pore Structure and Its Influence on Drying Shrinkage. Concrete is a porous aggregate, and its pores can be divided into gel pores, capillary pores, and stomata (macropores). Among them, the pore size of stomata is the largest at $1 \mathrm{~mm}$ to $0.01 \mathrm{~mm}$. However, stomata have little influence on concrete shrinkage. Capillary pores and gel pores have the greatest impact on concrete shrinkage, especially for those with sizes between $2.5 \mathrm{~nm}$ and $50 \mathrm{~nm}$. Pores with sizes between $50 \mathrm{~mm}$ and $100 \mathrm{~nm}$ also have some influence on concrete shrinkage. Therefore, the proportion of pores with the above two ranges can reflect the shrinkage ability of the concrete material [1215]. 


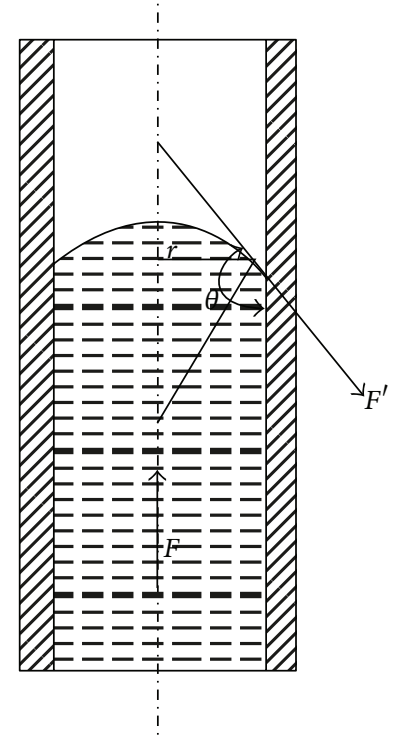

FIGURE 2: Diagram of pressing mercury into the pores.

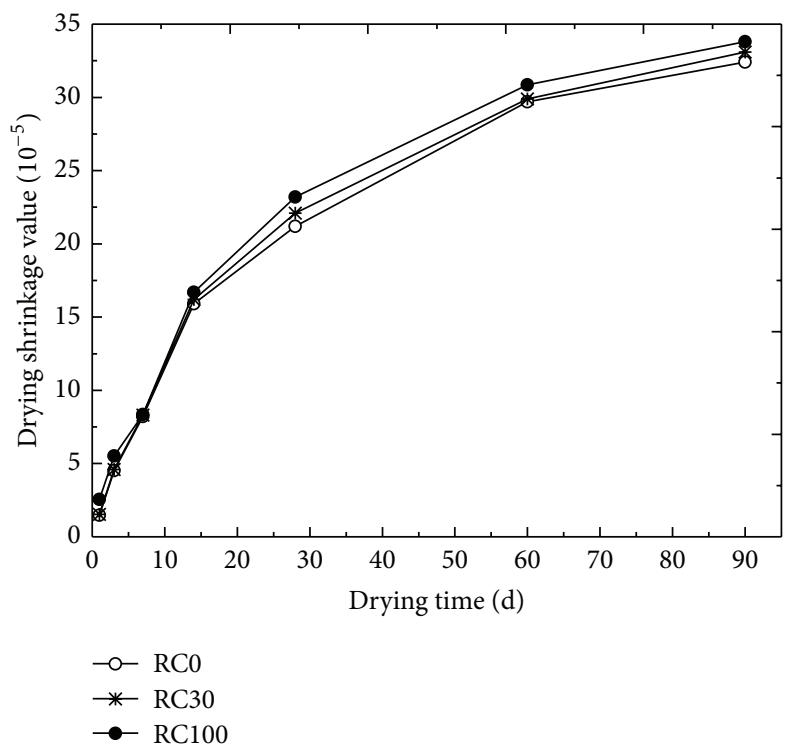

FIGURE 3: Influence of different RCA replacement ratios on RAC drying shrinkage.

Table 3 shows the effect of different pores on the properties of hardened cement paste.

3.2.1. Water Evaporation Method. The impact of recycled aggregate on the porosity of RAC in water evaporation is shown in Figure 4 [12].

Figure 4 shows that, with the increase in recycled aggregate replacement rate, the total porosity of RAC increases significantly. Compared with NAC, the increase in porosity of the capillary pores of RAC is evident.
3.2.2. Mercury Intrusion Method. For cement-based materials, drying shrinkage mainly comes from the drying shrinkage of cement stone. Hence, in the mercury test in this study, specimens were taken from a cement mortar section of RAC. The cumulative curve of pore volume test in mercury intrusion is shown in Figure 5.

Figure 5 and the test data show the sample RC0. The injection of mercury into the sample starts when the pore size is $45.352 \mu \mathrm{m}$. The intrusion volume of mercury per gram of samples is $0.0036 \mathrm{~mL} / \mathrm{g}$ when the mercury pressure is 1.994 psia. No mercury is reinjected into the sample when the pressure is 29992.57 psia. The pore-size range of RC0 is $3.015 \mu \mathrm{m}$ to $45.352 \mu \mathrm{m}$. Median radius is calculated according to the volume method; when intermediate interpolation is applied, the median radius is $34.2 \mathrm{~nm}$.

For sample RC30, mercury starts injecting into the sample when the pore size is $45.253 \mu \mathrm{m}$. The intrusion volume of mercury per gram of samples is $0.003 \mathrm{~mL} / \mathrm{g}$ when the mercury pressure is 1.998 psia. No mercury is reinjected into the sample when the pressure is 29992.48 psia. The poresize range of RC30 is $3.015 \mu \mathrm{m}$ to $45.252 \mu \mathrm{m}$. The median radius is calculated according to the volume method; when intermediate interpolation is applied, the median radius is $31 \mathrm{~nm}$.

For sample RC100, the injection of mercury into the sample starts when the pore size is $45.352 \mu \mathrm{m}$. The intrusion volume of mercury per gram of samples is $0.0022 \mathrm{~mL} / \mathrm{g}$ when the mercury pressure is 1.998 psia. No mercury is reinjected into sample when the pressure is 29992.5 psia. The poresize range of $\mathrm{RC100}$ is $3.015 \mu \mathrm{m}$ to $45.352 \mu \mathrm{m}$. The median radius is calculated according to the volume method; when intermediate interpolation is applied, the median radius is $34 \mathrm{~nm}$.

The Washburn equation shown in (2) is an important theoretical formula of mercury intrusion:

$$
r=\frac{-2 \sigma \cos \theta}{P},
$$

where $P$ is the applied pressure, $\mathrm{Pa} ; r$ is the radius of pore, $\mathrm{nm}$; $\sigma$ is the surface tension of mercury, $\mathrm{N} \cdot \mathrm{m}^{-1}$, and the surface tension of mercury is $0.48 \mathrm{~N} \cdot \mathrm{m}^{-1}$ at $20^{\circ} \mathrm{C}$; and $\theta$ is the wetting angle of mercury to solid surface, ${ }^{\circ}$, and the wetting angle of mercury to cement material is $125^{\circ}$.

In this experiment, the unit of pressure $P$ is psia and $1 \mathrm{MPa}=145$ psia. Equation (3) can be obtained after the unit conversion:

$$
r=\frac{-2 \sigma \cos \alpha}{P}=\frac{-2 \times 0.48 \times \cos 125^{\circ} \times 145 \mathrm{psia}}{P}=\frac{79.84}{P} .
$$

According to the formula $\operatorname{Pr}=-(2 \sigma \cos \theta)$, the openpore volume of specimen is expressed as $V$, and the openpore volume of specimen with radius between $r$ and $r+d r$ is expressed as $d V$. Thus, the pore-size distribution function (in volume) can be shown as

$$
f(r)=\frac{d V}{V d r}
$$


TABLE 3: Effect of different pores on the properties of hardened cement paste.

\begin{tabular}{|c|c|c|c|c|}
\hline Name & Diameter & Description & Role of water & Impact on performance \\
\hline \multirow{3}{*}{ Capillary pores } & $10-0.05 \mu \mathrm{m}$ & $\begin{array}{l}\text { Large capillary pores } \\
\text { (macropores) }\end{array}$ & $\begin{array}{l}\text { Performance such as volume } \\
\text { water }\end{array}$ & Permeability, diffusion \\
\hline & $50-10 \mathrm{~nm}$ & $\begin{array}{l}\text { Medium capillary pores } \\
\text { (large capillary pores) }\end{array}$ & $\begin{array}{l}\text { Generating small surface } \\
\text { tension }\end{array}$ & $\begin{array}{l}\text { Permeability when no macropores } \\
\text { exist, shrinkage when relative } \\
\text { humidity is greater than } 80 \%\end{array}$ \\
\hline & $10-2.5 \mathrm{~nm}$ & $\begin{array}{l}\text { Small, independent capillary } \\
\text { pores (small capillary pores) }\end{array}$ & $\begin{array}{l}\text { Generating large surface } \\
\text { tension }\end{array}$ & $\begin{array}{l}\text { Shrinkage when relative humidity is } \\
\text { between } 50 \% \text { and } 80 \%\end{array}$ \\
\hline \multirow[t]{2}{*}{ Gel pores } & $2.5-0.5 \mathrm{~nm}$ & Micropores & $\begin{array}{l}\text { Strong water absorption, no } \\
\text { planum semilunatum }\end{array}$ & $\begin{array}{l}\text { Shrinkage and performance in all } \\
\text { relative humidity ranges }\end{array}$ \\
\hline & $\leq 0.5 \mathrm{~nm}$ & Mezzanine space & & \\
\hline
\end{tabular}

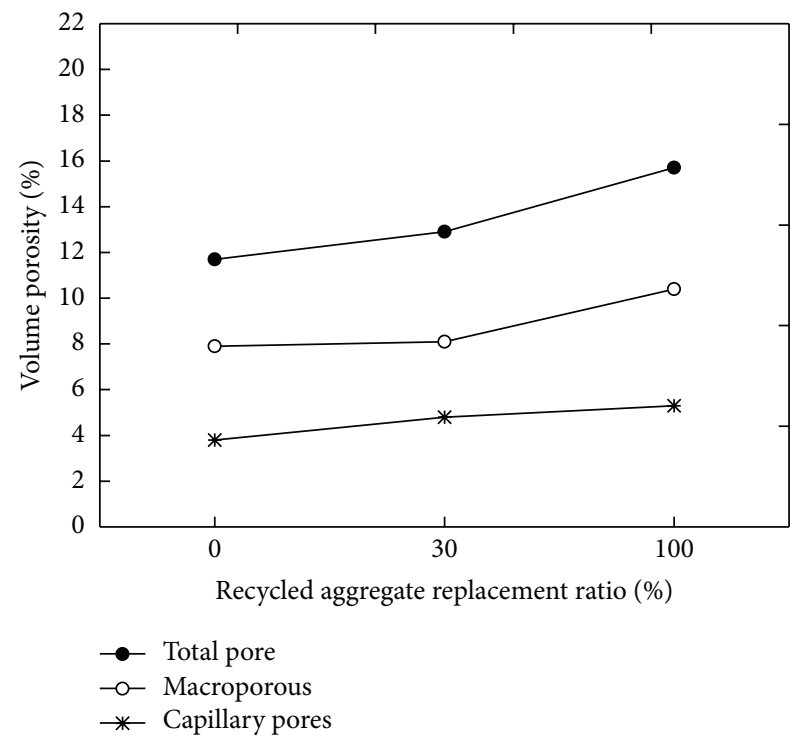

FIGURE 4: Influence of the recycled aggregate replacement ratio on the porosity of RAC.

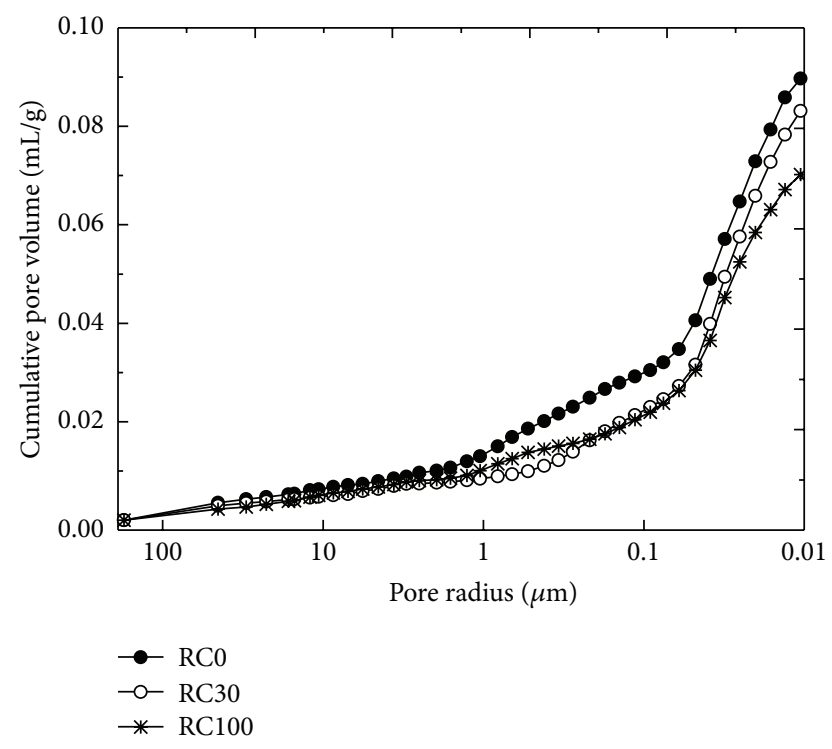

Figure 5: Cumulative curve of pore volume.
In the formula $\operatorname{Pr}=-(2 \sigma \cos \theta), \sigma$ and $\theta$ are constant. Hence, $P d r+r d P=0$. Therefore,

$$
f(r)=-\frac{P}{r V} \frac{d V}{d P} .
$$

Owing to the pore volume, what is measured directly with the instrument is the volume whose radius is greater than the $r$, which can be expressed as $V-V_{r}$, where $V$ is the total openpore volume and $V_{r}$ is the open-pore volume whose radius is smaller than $r$ in the specimen. If the pushed mercurycontent curve is depicted in the function of $V-V_{r}$ versus $P$, the curve slope $d\left(V-V_{r}\right) / d P=-d V / d P$ can be measured by the experiment. Hence, the above formula can be written as

$$
f(r)=\frac{P}{r V} \frac{d\left(V-V_{r}\right)}{d P} .
$$

The right-hand side value in (6) is known or can be measured, and the derivative in (6) can be solved by graphic differentiation to obtain $f(r)$. Finally, the pore-size distribution curve can be obtained by drawing point $r$ corresponding to the $f(r)$ value.

For convenience, directly measured data can be plotted in the cumulative pore-volume variation diagram of $\left(V-V_{r}\right) / V$ versus $P$ (shown in Figure 6 ) and the corresponding $r$ values attached to the $P$-axle. Thus, obtaining several $\Delta d$ intervals according to the need in the figure and finding the increment of $\left(V-V_{r}\right) / V$ in each corresponding interval, the pore-size distribution table can be listed as shown in Table 4.

Figure 6 and Table 4 show that as far as concrete mortar is concerned, the proportion of pores with sizes ranging from $3 \mathrm{~nm}$ to $100 \mathrm{~nm}$ is as follows: RC100 accounts for 95.3\%, and RC30 accounts for $94.9 \%$. Both are greater than that of RC0 (NAC) $87.9 \%$, which is consistent with the curve tendency in Figure 4, the main reason the shrinkage values of RAC is greater than natural concrete (as shown in Figure 3). However, pores greater than $10 \mu \mathrm{m}$ are smaller than those of natural concrete, which indicates that the addition of RCA mainly increases the content of capillary pores.

The proportions of various types of pores are different in water evaporation and in mercury intrusion, mainly because the different specimens were obtained in two ways. 


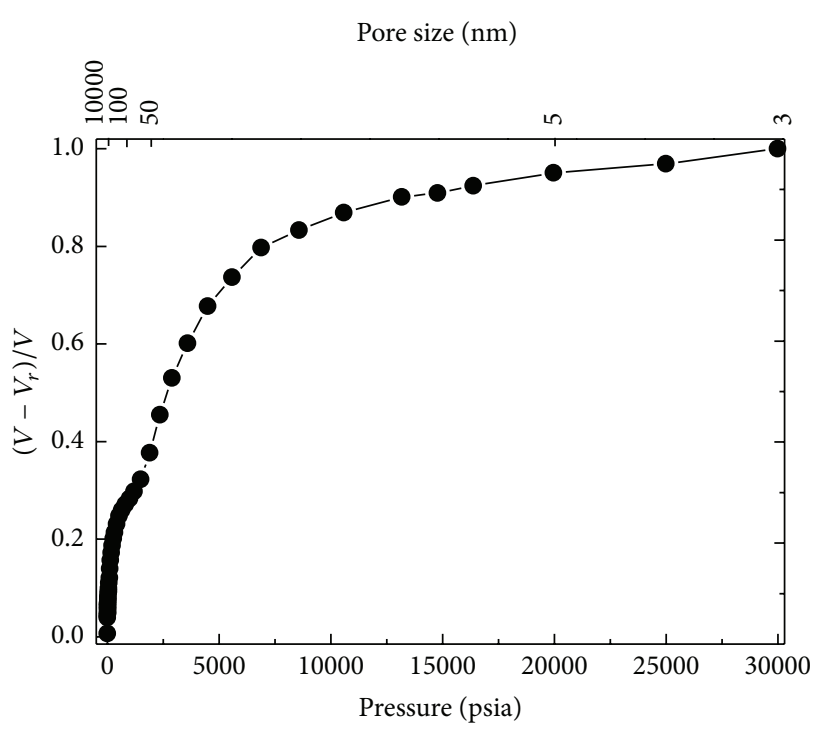

(a) RC0

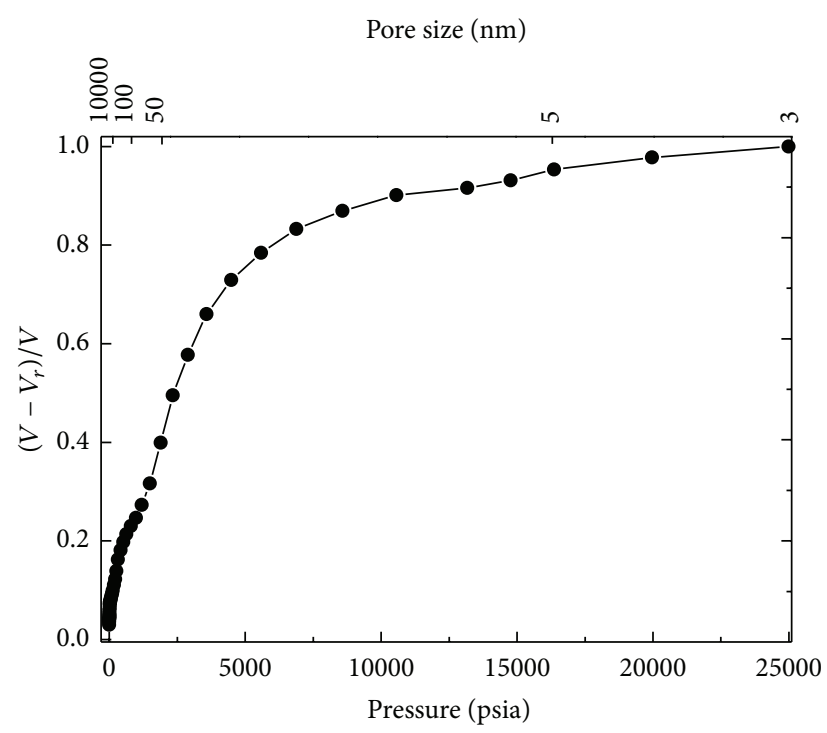

(b) RC30

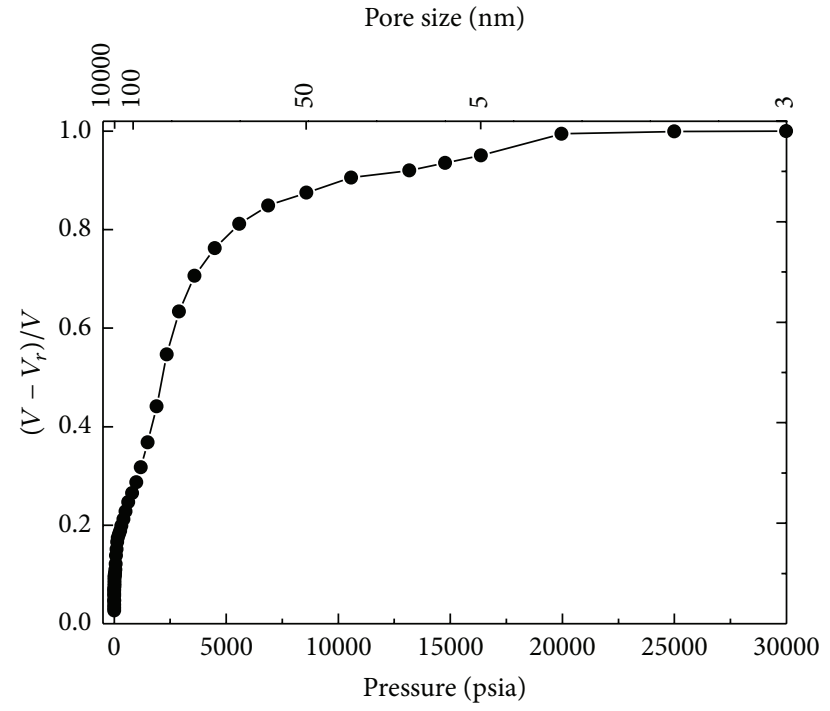

(c) R100

FIGURE 6: Cumulative curve of pore-size distribution of filter.

TABLE 4: Pore-size distribution of filter.

\begin{tabular}{|c|c|c|c|}
\hline \multirow{2}{*}{ Pore radius (nm) } & \multicolumn{3}{|c|}{ Distribution value (\%) } \\
\hline & $\mathrm{RC} 0$ & RC30 & $\mathrm{RC} 100$ \\
\hline$>10000$ & 12.1 & 5.1 & 4.7 \\
\hline $10000-100$ & 15.1 & 18.0 & 18.9 \\
\hline $100-50$ & 10.5 & 16.9 & 61.0 \\
\hline $50-5$ & 57.4 & 55.4 & 10.5 \\
\hline $5-3$ & 4.9 & 4.7 & 4.9 \\
\hline 3-100 Sum & 87.9 & 94.9 & 95.3 \\
\hline
\end{tabular}

3.3. Pore-Fractal Law. Pore geometry and particle geometry of concrete show the fractal behavior over the range of atom scale to grain size [16]. The introduction of fractal-dimension concept makes the quantitative description of concrete pore structure possible.

According to the fractal definition, the power-law relationship meets between the number of objects with the same scale and their measurement linear scales:

$$
N \propto r^{-D}
$$

where $N$ is the number of scale feature bodies accommodated in fractal objects; $r$ is the pore radius, $n m ; D$ is the fractal dimension of fractal objects; and $N=C^{-D}$, where $C$ is the proportional factor.

When a cylinder with the size of height $l$ and crosssectional radius $r$ is utilized to measure the pore volume $V_{m}$ of concrete, $V_{m}=N \times \pi r^{2} l$. Therefore,

$$
V_{m}=C \pi r^{2-D} l \text {. }
$$




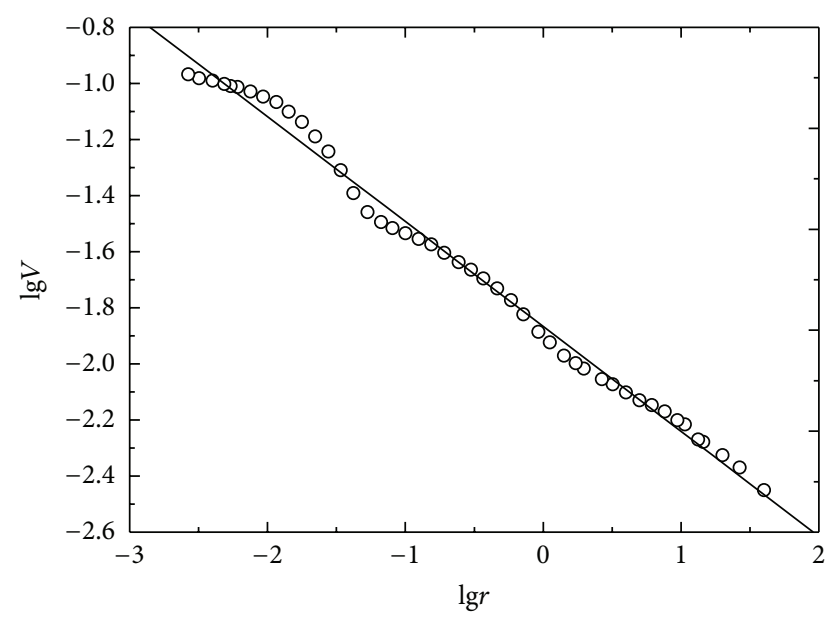

(a) RC0

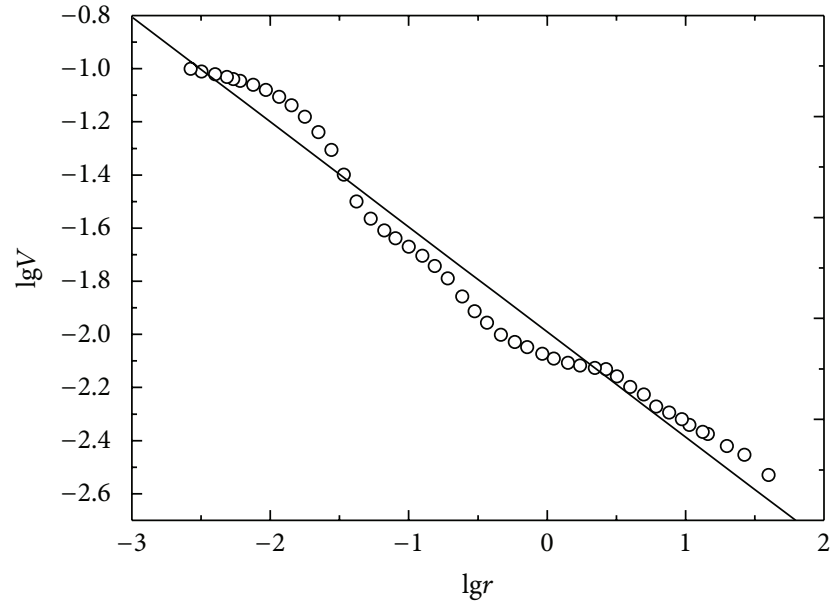

(b) RC30

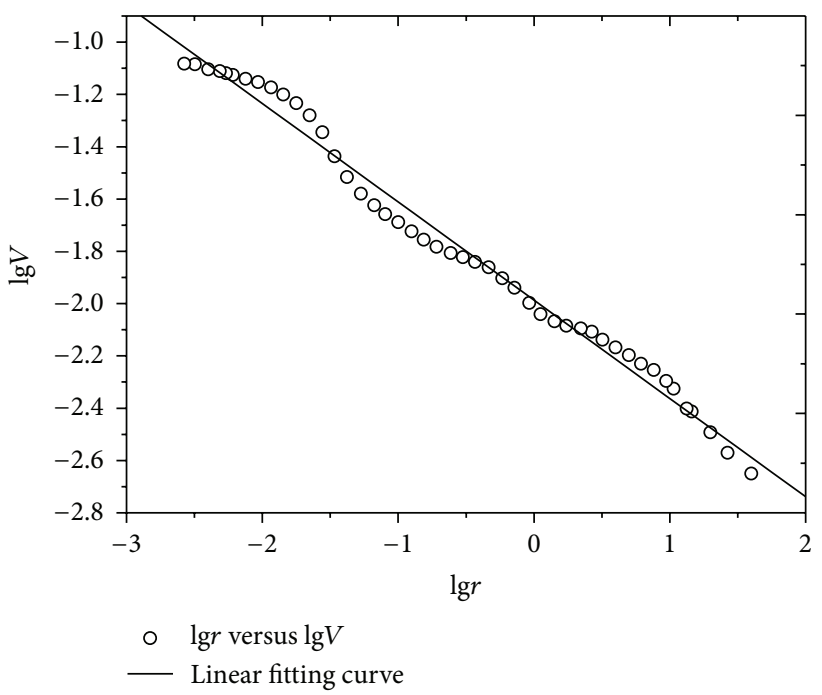

(c) RC100

Figure 7: Curve of pore-fractal law.

When (3) is substituted into (8), we have

$$
V_{m}=C \pi\left(\frac{79.84}{P}\right)^{2-D} l .
$$

Both sides of (9) are obtained logarithms; thus, we have

$$
\log \left(V_{m}\right)=(D-2) \times \log \left(\frac{P}{79.84}\right)+\log (C \pi l) .
$$

With both $\log (C \pi l)$ and $D-2$ as constants, $\log (P / 79.84)$ exhibits linear change along with $\log \left(V_{m}\right)$, and $K$ is the slope of the line. Thus,

$$
D=2+K \text {. }
$$

Therefore, the pore-fractal dimension $D$ can be determined by the straight-line slope $K$. As long as the linear relationship between $\log \left(V_{m}\right)$ and $\log (P / 79.84)$ exists, the pore-fractal dimension possesses the fractal feature of pore distribution.
Pressure $P$ and pore volume $V_{m}$ of concrete specimens can be obtained through mercury experiments. The corresponding $\log (P / 79.84)$ and $\log \left(V_{m}\right)$ are then calculated, the curve of $\log (P / 79.84)$ versus $\log \left(V_{m}\right)$ is drawn, and their linear fit is performed (as shown in Figure 7). Table 5 shows the fitting parameters and pore-fractal dimension of the sample.

Figure 7 and Table 5 show that linear-fitting correlation coefficients of the three curves are above 99\%, which indicates that the pore distribution of RAC meets the fractal feature. The fractal dimension of pore volume characteristics can be calculated according to the curve slope $K$. The pore-fractal dimension of RC0 is 1.605, RC30 is 1.626, and RC100 is 1.627. According to the fractal theory, if the pore-fractal dimension is higher, surface pores are more complex, which indicates that the complexity of the pore surfaces is RC30 > RC100 > $\mathrm{RC} 0$. Therefore, the addition of RCA increases the complexity of the pore surface of concrete. 
TABLE 5: Fitting parameters and pore-fractal dimension.

\begin{tabular}{lccc}
\hline No. & $K$ & $D=2+K$ & Correlation coefficient $R(\%)$ \\
\hline RC0 & -0.39532 & 1.605 & 99.65 \\
RC30 & -0.37408 & 1.626 & 99.64 \\
RC100 & -0.37492 & 1.625 & 99.37 \\
\hline
\end{tabular}

\section{Conclusions}

(1) With increase in RCA content, the drying shrinkage values increase gradually.

(2) The pore types with the greatest impact on concrete shrinkage are capillary and gel pores, especially for pores with sizes ranging from $2.5 \mathrm{~nm}$ to $50 \mathrm{~nm}$ and from $50 \mathrm{~nm}$ to $100 \mathrm{~nm}$. In the above two ranges, the proportions of RAC are greater than those of RC0 (NAC), which is the main reason the shrinkage values of RAC are greater than NAC.

(3) Through mercury intrusion analysis, the median radius of RC0 is $34.2 \mathrm{~nm}$, the median radius of RC30 is $31 \mathrm{~nm}$, and the median radius of $\mathrm{RC} 100$ is $34 \mathrm{~nm}$.

(4) The pore structure of RCA has good fractal feature, and the addition of RCA increases the complexity of the pore surface of concrete.

\section{Acknowledgments}

This project was supported by the Project of National Natural Science Foundation of China (51202304), Natural Science Foundation Project of CQ CSTC (cstc2012jjA50005), and Project of Science and Technology Committee of Wanzhou District of China (WZ011R003).

\section{References}

[1] Z. P. Bazant and F. H. Wittmann, Creep and Shrinkage in Concrete Structures, John Wiley \& Sons, New York, NY, USA, 1982.

[2] T. Shimomurat and K. Maekawa, "Analysis of the drying shrinkage behaviour of concrete using a micromechanical model based on the micropore structure of concrete," Magazine of Concrete Research, vol. 49, no. 181, pp. 303-322, 1997.

[3] S. Hasaba and M. Kawamure, "Drying shrinkage and durability of the concrete made of recycled concrete aggregate," Transactions of the Japan Concrete Institute, no. 3, pp. 55-60, 1981.

[4] A. Katz, "Properties of concrete made with recycled aggregate from partially hydrated old concrete," Cement and Concrete Research, vol. 33, no. 5, pp. 703-711, 2003.

[5] F. Debieb and S. Kenai, "The use of coarse and fine crushed bricks as aggregate in concrete," Construction and Building Materials, vol. 22, no. 5, pp. 886-893, 2008.

[6] L. Courard, F. Michel, and P. Delhez, "Use of concrete road recycled aggregates for roller compacted concrete," Construction and Building Materials, vol. 24, no. 3, pp. 390-395, 2010.

[7] A. Domingo-Cabo, C. Lázaro, F. López-Gayarre, M. A. SerranoLópez, P. Serna, and J. O. Castaño-Tabares, "Creep and shrinkage of recycled aggregate concrete," Construction and Building Materials, vol. 23, no. 7, pp. 2545-2553, 2009.
[8] L. Evangelista and J. Brito, "Durability performance of concrete made with fine recycled concrete aggregates," Cement and Concrete Composites, vol. 32, no. 1, pp. 9-14, 2010.

[9] V. Ngala and C. Page, "Effects of carbonation on pore structure and diffusional properties of hydrated cement pastes," Cement and Concrete Research, vol. 27, no. 7, pp. 995-1007, 1997.

[10] M. Saad, S. A. Abo-El-Enein, G. B. Hanna, and M. F. Kotkata, "Effect of temperature on physical and mechanical properties of concrete containing silica fume," Cement and Concrete Research, vol. 26, no. 5, pp. 669-675, 1996.

[11] C. Yong, Preparation and Characterization of Porous Materials, University of Science and Technology of China, Hefei, China, 2010.

[12] Y. X. He, "Experimental research on pore structure of RCA and its impact on drying shrinkage," Advanced Materials Research, vol. 335-336, pp. 1141-1144, 2011.

[13] W. Zhongwei, Expansive Concrete, China Railway, Beijing, China, 1990

[14] H. Guoxing, Shrinkage of Concrete, China Railway, Beijing, China, 1990

[15] W. Zhongwei, Shrinkage-Compensating Concrete, China Architecture \& Building Press, Beijing, China, 1979.

[16] J. Bingyou, L. Boquan, W. Haijin, Z. Chuanjie, and L. Zhenguo, "Structural characteristics and fractal laws research in coal and rock ultrafine pore," Journal of Hunan University of Science \& Technology, vol. 25, no. 3, pp. 15-18, 2010. 


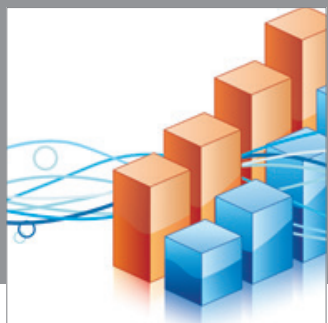

Advances in

Operations Research

mansans

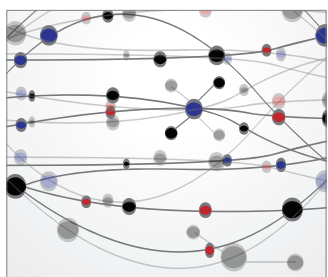

The Scientific World Journal
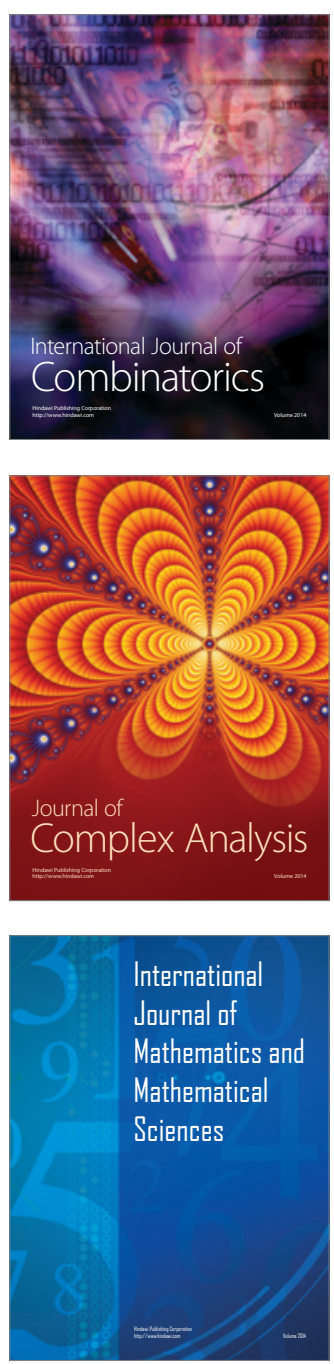
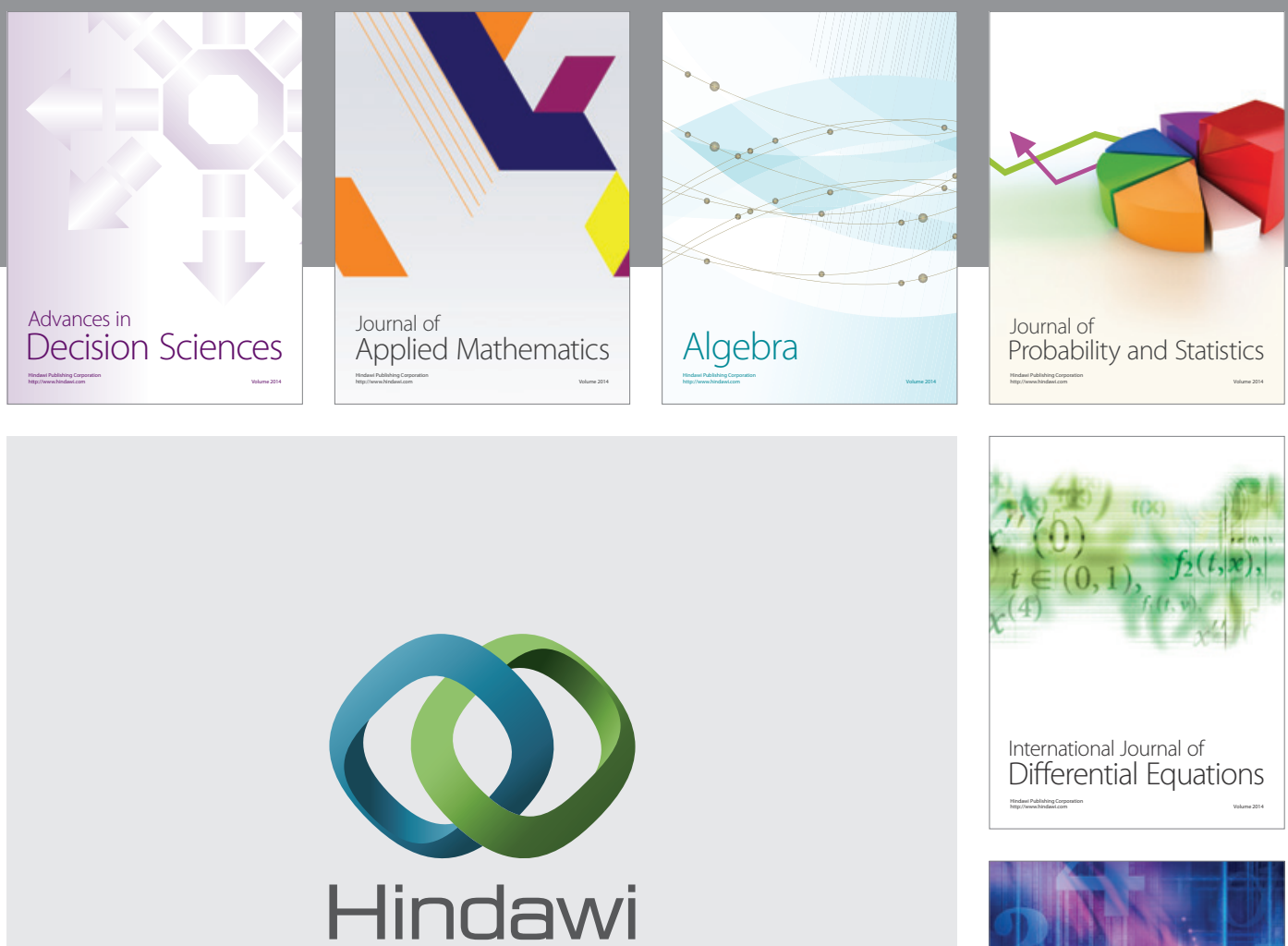

Submit your manuscripts at http://www.hindawi.com
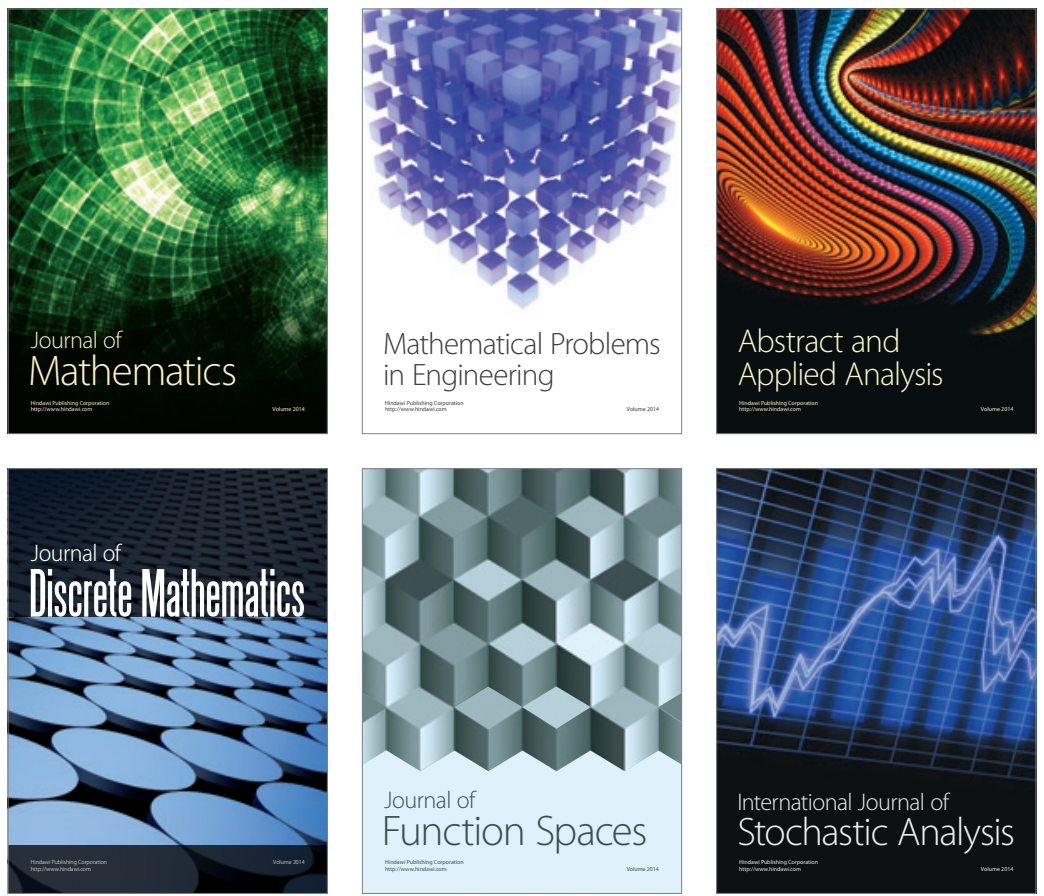

Journal of

Function Spaces

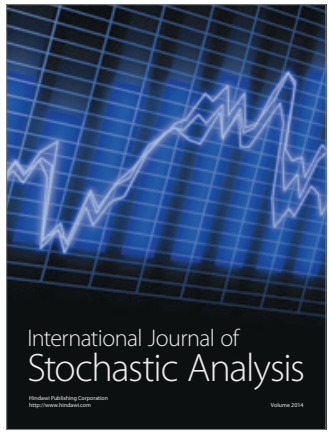

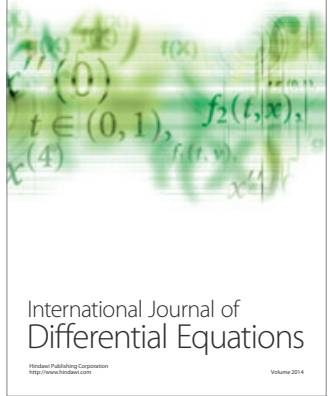
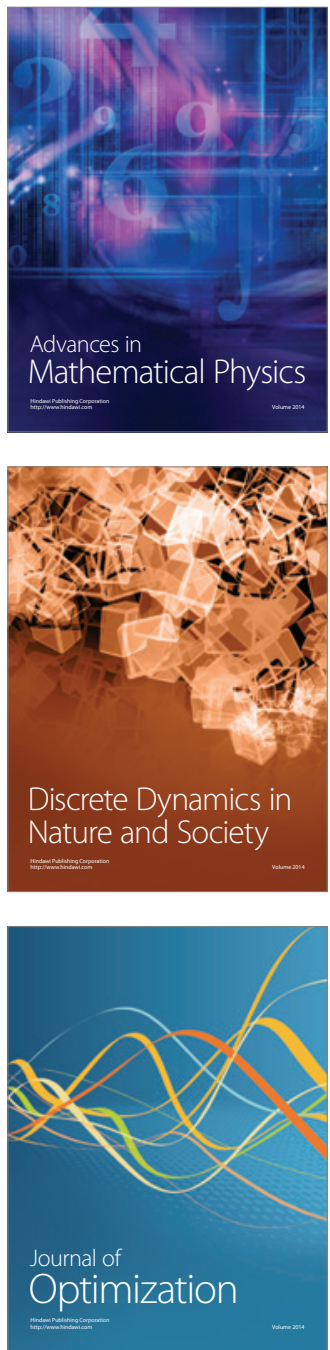